\title{
$\omega-{ }^{123}$ I-Hexadecanoic acid metabolic probe of cardiomyopathy
}

\author{
Mark A. Rabinovitch ${ }^{1}$, Victor Kalff ${ }^{2}$, Richard Allen, Amnon Rosenthal, James Albers, Sunil K. Das, Bertram Pitt, \\ Dennis P. Swanson, Thomas Mangner, W. Leslie Rogers, James H. Thrall, and William H. Beierwaltes \\ Divisions of Nuclear Medicine and Cardiology, Department of Internal Medicine, and the Sections of Pediatric Neurology, \\ and Pediatric Cardiology, Departments of Pediatrics and Neurology, University of Michigan Medical Center, Ann Arbor, USA
}

\begin{abstract}
The utility of $\omega^{-123} \mathrm{I}$-hexadecanoic aicd myocardial scintigraphy as a metabolic probe of cardiomyopathies was investigated. Sixteen patients with a variety of cardiomyopathies and myopathies that involve cardiac muscle and ten volunteers were imaged in the postabsorptive state in a $40^{\circ} \mathrm{LAO}$ projection after a standard dose of $\omega-^{123} \mathrm{I}$ hexadecanoic acid. An elimination $\mathrm{T}_{1 / 2}$ was calculated from the left ventricular myocardial time-activity curve. An uptake index, corrected for chest wall attenuation, was also computed in 7 of 10 volunteers and 8 of 16 patients.

Of the 16 patients, only 2 had distinctly abnormal $\omega-{ }^{123}$ I-hexadecanoic acid myocardial tracer kinetics. The first patient had a metabolic disorder of which carnitine deficiency was one component. The second patient had endocardial fibroelastosis, a process which has been linked to disorders which deprive the myocardium of oxygen and energy. Therefore, the cardiomyopathy may have been caused by some abnormality of cardiac metabolism other than carnitine deficiency. Although of limited utility in the overall cardiomyopathic population, $\omega^{-123}$ I-hexadecanoic acid myocardial scintigraphy should be further investigated as a screening test for carnitine deficiency and related metabolic abnormalities in patients at risk.
\end{abstract}

The cardiomyopathies are a group of myocardial disorders of diverse etiology and pathophysiology (Goodwin et al. 1982). They account for a significant percentage of cardiac morbidity and mortality. In a small number of cases, the cardiomyopathy can be traced to some inborn error of cardiac metabolism (Goodwin et al. 1982; Taylor 1982). Since certain of these defects such as carnitine deficiency (Engel 1980) may be amenable to specific therapy, their clinical identification is of great importance. Unfortunately, the tools available to the clinician for the work-up of patients presenting with cardiomyopathy are limited. Echocardiography and cardiac blood pool scintigraphy can provide important anatomical and physiological information, but are

1 Supported by a Canadian Heart Foundation Research Fellowship

2 Supported by an Australian Heart Foundation Travel Grant

offprint requests to: Mark A. Rabinovitch, MD, Division of Cardiology, The Montreal General Hospital, 1650 Cedar Avenue, Montreal, Quebec H3G 1A4, Canada lacking when an etiological diagnosis is sought. Myocardial biopsy has been useful for the detection of inflammatory processes and amyloidosis (Melvin and Mason 1982), and potentially could be used to diagnose metabolic defects as well (Peters et al. 1977). However, its invasive nature is a detraction. Also, patchy disease can often be missed when a tiny endomyocardial biopsy is taken (Ferrans and Roberts 1978).

Myocardial imaging with radiolabeled metabolic tracers might provide an important noninvasive means of identifying metabolic defects in the cardiomyopathies. The state of myocardial fatty acid metabolism can be depicted by the myocardial tracer kinetics of positron emitting ${ }^{11} \mathrm{C}$-palmitate (Klein et al. 1979; Lerch et al. 1982; Schön et al. 1982). Positron emission tomography with ${ }^{11} \mathrm{C}$-palmitate has thus enabled the in vivo study of myocardial fatty acid metabolism in the relatively few centers equipped with an onsite cylotron (Lerch et al. 1981; Schelbert et al. 1983). An alternative, more widely applicable method involves the imaging of radioiodinated long chain fatty acid substrates with an Anger camera. Terminally radioiodinated long chain fatty acids have been found to be extracted and cleared by the myocardium in a fashion similar to carbon labeled counterparts (Machulla et al. 1978). Using the conventional gamma camera, the elimination $T_{1}$ of these $\omega-{ }^{123}$ I-fatty acids has been quantified in man (Freundlieb et al. 1980). Abnormal regional myocardial tracer kinetics have been observed during exercise-induced ischemia (van der Wall et al. 1981), unstable angina (van der Wall et al. In press), and acute myocardial infarction (van der Wall et al. 1981). The aim of this study was to determine whether $\omega^{-123}$ I-hexadecanoic acid myocardial scintigraphy might be useful for the detection of myocardial metabolic defects in patients with cardiomyopathy.

\section{Materials and methods}

\section{Study Population}

$\omega^{-123}$ I-hexadecanoic acid myocardial scintigraphy was performed in a group of ten healthy adult volunteers to establish normal ranges for myocardial tracer kinetics. There were eight males and two females with a mean age of 26 years, range $23-40$ years (Table 1 ). Then sixteen patients with a variety of cardiomyopathies and neuromyopathies that involve cardiac muscle were studied (Table 2). 
Patient 1 had the Kearns-Sayre syndrome, a disorder characterized by: (a) progressive external ophthalmoplegia, (b) pigmentary retinal degeneration, and (c) heart block (Kearns et al. 1958; Berenberg et al. 1977). Although she had not yet developed heart block, there was a left anterior hemiblock and an incomplete right bundle branch block. Since this patient had clinical similarities to previously reported patients with folic acid malabsorption (Lanzkowsky et al. 1969) and in view of the recent evidence linking folic acid and carnitine metabolism (Allen et al. 1980), plasma folate (Rothenberg et al. 1972) and skeletal muscle carnitine (McGarry and Foster 1976) were measured in this patient. These studies showed: (a) a low plasma folate level of $1.9 \mathrm{ng} / \mathrm{ml}$ (normal $5-15 \mathrm{ng} / \mathrm{ml}$ ), (b) ragged-red fibers on a skeletal muscle biopsy, (c) subnormal skeletal muscle free carnitine of $2.70 \mathrm{nmol} / \mathrm{mg}$ noncollagen protein (normal

Table 1. $\omega^{-123}$ I-Hexadecanoic acid myocardial uptake-washout indices of volunteers

\begin{tabular}{lllll}
\hline No. & Sex & $\begin{array}{l}\text { Age } \\
(\mathrm{yrs})\end{array}$ & $\begin{array}{l}\text { Myocardial } \\
T_{1 / 2}(\mathrm{~min})\end{array}$ & $\begin{array}{l}\text { Myocardial } \\
\text { uptake index }\end{array}$ \\
\hline 1 & F & 40 & 39 & 61.9 \\
2 & $\mathrm{M}$ & 27 & 29 & 65.0 \\
3 & $\mathrm{M}$ & 24 & 30 & 77.9 \\
4 & $\mathrm{M}$ & 24 & 21 & \\
5 & $\mathrm{~F}$ & 24 & 36 & \\
6 & $\mathrm{M}$ & 24 & 26 & 45.3 \\
7 & $\mathrm{M}$ & 23 & 41 & 64.1 \\
8 & $\mathrm{M}$ & 23 & 27 & 58.6 \\
9 & $\mathrm{M}$ & 23 & 32 & 60.6 \\
10 & $\mathrm{M}$ & 26 & 44 & \\
Mean \pm SD & & $26 \pm 5$ & $33 \pm 7$ & $62 \pm 10$ \\
\hline
\end{tabular}

a The myocardial uptake index, corrected for chest wall attenuation, is expressed in counts/pixel/min
$17.10 \pm 7.6 \mathrm{nmol} / \mathrm{mg}$ based on 35 controls) and slightly increased esterified carnitine content. Skeletal muscle carnitine levels were performed in the laboratory of Dr. Salvatore Di Mauro by a modification of the method of McGarry and Foster (1976).

Patient 2 was a 2-year-old female with severe congestive heart failure since the age of 6 weeks. Cardiac catherization was suggestive of endocardial fibroelastosis. She died within a week of $\omega{ }^{123}$ I-hexadecanoic acid myocardial scintigraphy. Postmortem examination revealed endocardial fibroelastosis, myocardial hypertrophy, and extensive myocardial fibrosis. She had a skeletal free muscle carnitine of $2.03 \mathrm{mmol} / \mathrm{g}$ wet tissue and cardiac free muscle carnitine of $0.64 \mathrm{mmol} / \mathrm{g}$ wet tissue. Both these values are within the normal range.

Table 2 lists the other patients studied with their diagnoses and noninvasive assessment of left ventricular function. As can be seen, a full spectrum of cardiomyopathies and myopathies which involve cardiac muscle was studied. Also, left ventricular function varied widely within the patient group.

\section{Imaging methods}

$\omega-{ }^{123} \mathrm{I}$-hexadecanoic acid was synthesized by iodine replacement labeling of 16-bromohexadecanoic acid in refluxing methylethyl ketone followed by evaporation to dryness and formulation in sterile, pyrogen-free 5\% HSA solution (Otto et al. 1981). The ${ }^{123}$ I utilized for this synthesis was produced by the ${ }^{127} \mathrm{I}(\mathrm{p}, 5 \mathrm{n}){ }^{123} \mathrm{Xe} \rightarrow{ }^{123} \mathrm{I}$ reaction with radionuclide purity specification of $98.6 \%{ }^{123} \mathrm{I}$ and $1.4 \%{ }^{125} \mathrm{I}$ at the time of calibration. ${ }^{123} \mathrm{I}$ was obtained from Crocker Laboratories, Davis, Calif. Radiochemical purity of the final preparation was greater than $95 \%$ as determined by anion exchange chromatography using Bio Rad AG1-X8 resin preluted with $5 \%$ HSA solution.

Table 2. $\omega^{-123}$ I-Hexadecanoic acid myocardial kinetics of patients

\begin{tabular}{|c|c|c|c|c|c|c|c|c|c|}
\hline \multirow[t]{2}{*}{ Number } & \multirow[t]{2}{*}{ Sex } & \multirow[t]{2}{*}{ Age } & \multirow[t]{2}{*}{ Diagnosis } & \multicolumn{2}{|c|}{ LV function } & \multicolumn{2}{|l|}{$T_{1 / 2}$} & \multicolumn{2}{|c|}{ Uptake index } \\
\hline & & & & $\begin{array}{l}\text { Fract. } \\
\text { shortening }\end{array}$ & LVEF & $\min$ & $Z$ score $^{\mathrm{a}}$ & $\begin{array}{l}\text { counts/ } \\
\text { pixel/min }\end{array}$ & $Z$ score \\
\hline 1 & $\mathrm{~F}$ & 24 & KSS + carnitine deficiency & 36 & & 60 & +3.9 & 27.9 & -3.4 \\
\hline 2 & $\mathrm{~F}$ & 2 & $\mathrm{CM}+$ endocardial fibroelastosis & 10 & 23 & 105 & +10.3 & & \\
\hline 3 & $\mathrm{~F}$ & 20 & Progressive ext. ophthalmoplegia & & & 15 & -2.6 & & \\
\hline 6 & $\mathrm{~F}$ & 27 & Myotonic dystrophy & 34 & & 20 & -1.9 & 29.8 & -3.2 \\
\hline 7 & $\mathrm{M}$ & 50 & Myotonic dystrophy & & & 20 & -1.9 & & \\
\hline 8 & $\mathrm{M}$ & 35 & Myotonic dystrophy & 40 & & 20 & -1.9 & 28.5 & -3.4 \\
\hline 9 & $\mathrm{M}$ & 24 & Freidreich's ataxia & 38 & & 31 & -0.3 & & \\
\hline 10 & $\mathrm{~F}$ & 14 & Congestive $\mathrm{CM}+$ mitral regurg & & 14 & 39 & +0.9 & 30.1 & -3.2 \\
\hline 11 & $\mathrm{~F}$ & 58 & Congestive CM & & 27 & 34 & +0.1 & & \\
\hline
\end{tabular}

Abbreviations: $\mathrm{KSS}=$ Kearns Sayre syndrome, $\mathrm{CM}=$ cardiomyopathy, ext $=$ external, regurg $=$ regurgitation, fib $=$ fibrillation, $\mathrm{LV}=\mathrm{left}$ ventricular, Fract $=$ fractional, $L V E F=$ left ventricular ejection fraction.

Fractional shortening was determined by echocardiography and left ventricular ejection fraction by gated cardiac blood pool scintigraphy.

a $\mathrm{Z}$ score $=$ number of standard deviations beyond the normal mean 
All volunteers and patients were studied in the postabsorptive state (at least $4 \mathrm{~h}$ from the last meal) after ingesting SSKI to block thyroidal uptake of the tracer. All adults received a standard 3-mCi dose and all pediatric patients received the equivalent dose adjusted to body surface area. Images were obtained in the $40^{\circ}$ left anterior oblique projection with a standard field of view gamma camera, mediumenergy parallel-hole collimator $(360 \mathrm{KeV})$, employing a $20 \%$ window around the $159 \mathrm{KeV}$ photopeak of ${ }^{123} \mathrm{I}$. Beginning with injection of the tracer, serial 1-min images were acquired in a $64 \times 64$ word mode for $30 \mathrm{~min}$.

\section{Data analysis}

Data processing was identical for all studies. From the composite $30 \mathrm{~min}$ image a myocardial region of interest was flagged encompassing both ventricles. Then, all 1-min raw images were subjected to horizontal interpolative background subtraction by a modification of the method of Watson et al. (1981). Next, a time-activity curve of the left ventricular myocardium excluding the inferoapical segment was generated from the processed images. The inferoapical segment was excluded to avoid the problem of hepatic overlap which occurred in some patients. An elimination $\mathrm{T}_{1 /}$ was determined by plotting the curve on semilog paper and subjecting the straight downsloping part beyond $6 \mathrm{~min}$ to a monoexponential least squares fit. An uptake index was derived by first summing images 6-10 and calculating the average counts/pixel/min over the left ventricular moycardium excluding the inferoapical segment. To correct for chest wall attenuation, this value was then divided by $e^{-\mu \mathrm{d}}$, where $\mu$ is the linear attenuation coefficient of ${ }^{123} \mathrm{I}$ in water and $d$ is the distance in $\mathrm{cm}$ from the surface of the chest to the mid-left ventricular cavity measured on a parasternal long-axis M-mode echocardiogram.

\section{Results}

\section{Normal volunteers and patients}

The $\omega{ }^{123}$ I-hexadecanoic acid myocardial tracer kinetics of the volunteers are shown in Table 1 . The mean elimination $T_{1 / 2}$ was $33 \pm 7 \mathrm{~min}$ with a range of $21-44 \mathrm{~min}$. The mean attenuation corrected uptake index was $62 \pm 10$ counts/ $\mathrm{pixel} / \mathrm{min}$ with a range of $45-78$. The $\omega^{-123} \mathrm{I}$-hexadecanoic acid myocardial tracer kinetics of the patients are shown in Table 2. Only 2 of the 16 patients had a markedly prolonged $T_{1 / 2}$. Patient 1 with Kearns Sayre syndrome and carnitine deficiency had a $T_{1 / 2}$ of $60 \mathrm{~min}$. Patient 2 with idiopathic cardiomyopathy and endocardial fibroelastosis had a elimination $T_{1 / 2}$ of $105 \mathrm{~min}$. Three patients had a very slightly accelerated $T_{1 / 2}$ : patient 5 , the 2-year-old female with myotonic dystrophy and patient 16 , the 1 -year-old female with complex congenital heart disease, had a $T_{1 / 2}$ of $16 \mathrm{~min}$, and patient 3 with progressive external ophthalmoplegia had a $T_{1 / 2}$ of $15 \mathrm{~min}$. All other patients had a $T_{1 / 2}$ within 2 standard deviations of the normal mean.

Attenuation corrected uptake indices are also listed in Table 2. Pediatric patients were excluded from the uptake index analysis for lack of suitable controls. Patient 1 with Kearns Sayre syndrome and carnitine deficiency had the most depressed uptake index -28 counts/pixel $/ \mathrm{min}$. Patients 6 and 7 with myotonic dystrophy and patient 12 with idiopathic congestive cardiomyopathy and severe mitral re-
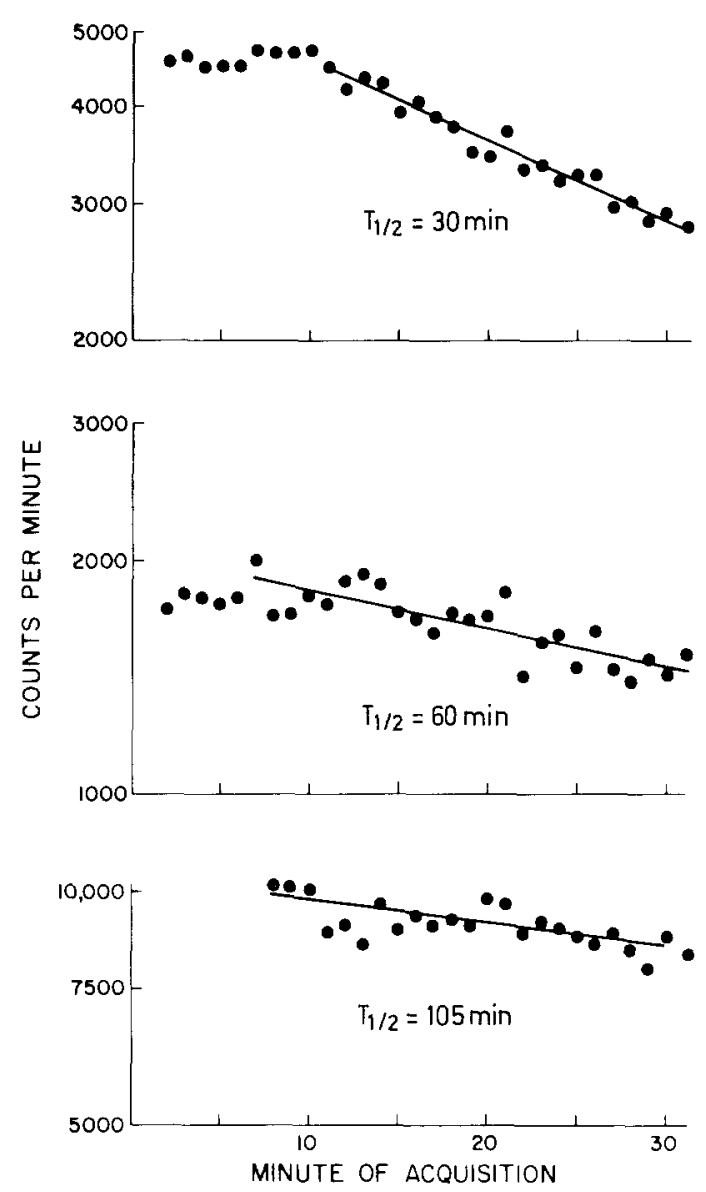

Fig. 1. Contrasts the myocardial time-activity curves of a representative volunteer (top), patient 1 with Kearns Sayre syndrome and carnitine deficiency (middle), and patient 2 with idiopathic cardiomyopathy and endocardial fibroelastosis (bottom)

gurgitation also had depressed uptake indices. Patient 14 with hypertrophic obstructive cardiomyopathy had a slightly increased uptake index.

Figure 1 depicts the myocardial time-activity curves of a representative volunteer (top), patient 1 with Kearns Sayre syndrome and carnitine deficiency (middle), and patient 2 with idiopathic cardiomyopathy and endocardial fibroelastosis (bottom).

In Fig. 2, early and late smoothed images of patient 1 are contrasted with the corresponding images of a normal volunteer. There is a lower count density in the patient's myocardial images and less of a change in myocardial activity between early and late images in comparison with the normal example. Also note that the patient's hepatic activity was eliminated at a faster rate than her myocardial activity, the reverse of what is normally found.

\section{Discussion}

At the outset, it was hoped that various patterns of $\omega)^{123} \mathrm{I}-$ hexadecanoic acid myocardial tracer kinetics would be identified in this diverse patient group. However, strikingly abnormal $\omega-{ }^{123}$ I-hexadecanoic acid myocardial tracer kinetics were observed in only 2 of the 16 patients studied.

Markedly reduced uptake and slowed washout of tracer was found in patient 1 with Kearns Sayre syndrome and carnitine deficiency. Carnitine is a quarternary amine essen- 


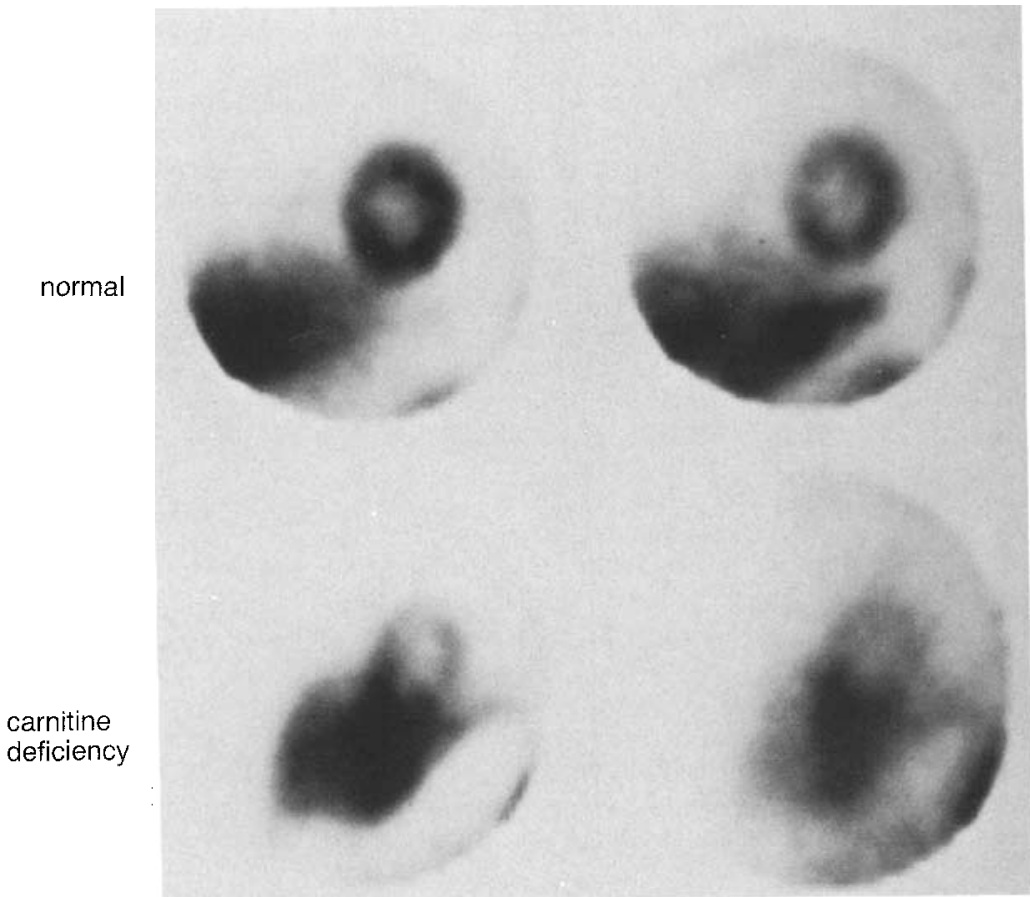

Fig. 2. Contrasts the $\omega^{-123} I$-hexadecanoic acid myocardial images of a normal volunteer (top) with those of patient 1 (bottom). The early images (left) are derived by summing raw 1-min images 5-15 and the late images (right) are derived by summing raw 1-min images 20-30 tial for the transfer of cytoplasmic long chain fatty acids to their mitochondrial site of $\beta$-oxidation (Frenkel and McGarry 1980). Carnitine deficiency has been identified as a cause of myopathy and potentially fatal cardiomyopathy (Chapoy et al. 1980; DiMauro et al. 1980; Engel 1980). Although patient 1 lacked the striking left ventricular dilation and hypofunction which has been reported in some patients with carnitine deficiency (Chapoy et al. 1980; Tripp et al. 1981), she did have a cardiac conduction defect and mild left ventricular hypertrophy by echocardiography. The $\omega-{ }^{123}$ I-hexadecanoic acid myocardial tracer kinetic pattern observed indicates that the technique was sensitive to this patient's abberrant long chain fatty acid metabolism. The alternative explanation that the results simply reflected reduced myocardial blood flow in this patient was considered unlikely. Abnormalities in coronary anatomy have not been documented in any previously described patients with a carnitine deficiency state (Frenkel and McGarry 1980).

Extremely slow washout of tracer was observed in patient 2 with fatal idiopathic cardiomyopathy and endocardial fibroelastosis. Endocardial fibroelastosis is often related to conditions causing myocardial hypoxia such as anomalous coronary artery circulation (Hastreiter 1968). Its familial occurrence suggests that endocardial fibroelastosis can also occur secondary to inborn errors of cardiac metabolism (Westwood et al. 1975). In one recently reported family, carnitine deficiency was found to be the cause (Tripp et al. 1981). Thus myocardial energy deprivation, either due to hypoxia, carnitine deficiency, or some other metabolic defect appears to be an important pathogenetic mechanism for this process. Of note, patient $2 \mathrm{had}$ a normal coronary angiogram as well as normal skeletal and cardiac muscle free carnitine in specimens obtained immediately post mortem. It is likely that the severely retarded $\omega-{ }^{123} \mathrm{I}$-hexadecanoic acid myocardial washout reflected some metabolic defect other than carnitine defi- ciency rather than a reduced myocardial blood flow in this patient.

$\omega-{ }^{123}$ I-hexadecanoic acid myocardial scintigraphy was normal or marginally abnormal in the remaining 14 patients studied. Patient 3 with progressive external ophthalmoplegia had pigmentary retinal degeneration but no evidence of a generalized myopathy and no cardiac involvement. Therefore, the biochemical defect underlying the syndrome may not have involved cardiac muscle. No distinctly abnormal $\omega-{ }^{123}$ I-hexadecanoic acid myocardial tracer kinetics emerged from patients 4-9 with a variety of heredofamilial neuromyopathies having cardiac expression (Duchenne's muscular dystrophy, myotonic dystrophy, Friedreich's ataxia). Recently, positron emission computed tomography with ${ }^{18} \mathrm{~F}$ 2-fluorodeoxyglucose revealed accelerated regional exogenous glucose utilization in the posterobasal and posterolateral walls in patients with Duchenne's muscular dystrophy (Perloff et al. 1984). Whether an accompanying decline in regional fatty acid metabolism exists, remains to be proven. Such a defect could have been missed in patient 4 because the $40^{\circ}$ left anterior oblique projection utilized in this study, did not permit optimal visualization of the posterobasal wall of the left ventricle. The somewhat low $\omega-{ }^{123} I$-hexadecanoic acid myocardial uptake index in two of the four patients with myotonic dystrophy is of uncertain significance.

Patients 10-14 had a variety of cardiomyopathies with a wide range of resting left ventricular function. Only patient 10 had a depressed $\omega^{-123}$ I-hexadecanoic acid myocardium uptake index. Interestingly, this patient had the lowest left ventricular ejection fraction $(14 \%)$. These results differ from those of Höck et al. (1983) who reported delayed $\omega-{ }^{123} \mathrm{I}$-heptadeconoic acid washout in the majority of their patients with severe congestive cardiomyopathy and normal or marginally delayed washout in patients with early stage cardiomyopathy. 
Patient 15 had paroxysmal atrial fibrillation and a history of alcohol abuse. Alcohol is known to impair acutely fatty acid oxidation (Bing 1978). The fact that this patient had abstained from alcohol for several months and had good ventricular function at the time of this study, may explain the normal myocardial tracer kinetics observed. Finally, patient 16 with congenital heart disease (double outlet right ventricle and valvular pulmonic stenosis) had intrinsically normal left ventricular muscle. Therefore, normal myocardial tracer kinetics were to be expected.

\section{Conclusions}

The results of this study have both disappointing and promising aspects. No distinctly abnormal patterns of $\omega^{-123} \mathrm{I}$ hexadecanoic acid myocardial tracer kinetics emerged from the patients with common types of cardiomyopathy, e.g. congestive cardiomyopathy, hypertrophic obstructive cardiomyopathy, or heredofamilial neuromyopathy. It is therefore unlikely that $\omega^{123} \mathrm{I}$-hexadecanoic acid myocardial scintigraphy will be clinically useful in classifying human cardiomyopathies on the basis of fatty acid metabolic patterns. The positive aspect of this study was the fact that $\omega \omega^{-123} \mathrm{I}$-hexadecanoic acid myocardial scintigraphy singled out patients 1 and 2 from the entire group of 16. Patient 1 had a carnitine deficiency state known to impair the intracellular transport of long chain fatty acids and patient 2 may have had a related defect in cardiac metabolism. While carnitine deficiency and related metabolic abnormalities are thought to be rare congenital conditions, they are potentially treatable causes of cardiomyopathy (Engel 1980; Mastaglia et al. 1980). Also, acquired carnitine deficiency has been found in more commonly encountered clinical settings such as uremia (Bohmer et al. 1978). The potential of $\omega^{-123}$ I-hexadecanoic acid myocardial scintigraphy as a noninvasive screening test for carnitine deficiency states in patients at risk should therefore be explored.

Acknowledgments. We would like to thank Dr. S. DiMauro for performing the carnitine assays in the Neuromuscular Research Laboratory, Columbia Presbyterian Medical Center. We thank Ms. Marjorie Rich, Mrs. Kathleen Worthington and Lawrence Brown, MS, for their excellent technical assistance, and Mrs. Karen Maki and Ms. Jean Walker for preparation of this manuscript. We are grateful to Mrs. Holly Anderson-Davis and Mr. John Jones of the Phoenix Memorial Project for their technical assistance in the preparation of the radiolabeled compound.

\section{References}

Allen RJ, Wong P, Rothenberg S, DiMauro S, Headington JT (1980) Progressive neonatal leukoence-phalomyopathy due to absent methylene-tetrahydrofolate reductase responsive to treatment. Ann Neurol (Abstract) 8:22

Berenberg RA, Pellock JM, DiMauro S, Schotland DL, Bonilla E, Eastwood A, Hays A, Vicale CT, Behrens M, Chutorian A, Rowland LP (1977) Lumping or splitting? "Ophthalmoplegia - plus" or Kearns-Sayre syndrome? Am Neurol 1:37-54

Bing RJ (1978) Cardiac metabolism: its contributions to alcoholic heart disease and myocardial failure. Circulation 58:965-970

Bohmer T, Bergrem H, Eiklind K (1978) Carnitine deficiency induced during intermittent haemodialysis for renal failure. Lancet $1: 126$

Chapoy PR, Angelini C, Brown WJ, Stiff JE, Shug AS, Cederbaum SD (1980) Systemic carnitine deficiency - A treatable inherited lipid-storage disease presenting as Reye's syndrome. N Engl J Med 303:1389-1394
DiMauro S, Trevisan C, Hays A (1980) Disorders of lipid metabolism in muscle. Muscle Nerve 3:369-380

Engel AG (1980) Possible causes and effects of carnitine deficiency in man. In: Frenkel RA, McGarry JD (eds) Carniture biosynthesis, metabolism and functions. Academic Press Inc, New York, p 271-284

Ferrans VJ, Roberts WC (1978) Myocardial biopsy: a useful diagnostic procedure or only a research tool? Am J Cardiol 41:965-967

Frenkel RA, McGarry JD (eds) (1980) Carnitine biosynthesis, metabolism and functions. Academic Press Inc, New York

Freundlieb $\mathrm{CH}$, Höck A, Vyska $\mathrm{K}$, Feinendegen LE, Machulla H-J, Stocklin G (1980) Myocardial imaging and metabolic studies with $\left[17-{ }^{123} \mathrm{I}\right]$ iodoheptadecanoic acid. J Nucl Med 21: $1043-1050$

Goodwin JF, Roberts WC, Wenger NK (1982) Cardiomyopathy. In: Hurst JW (ed) The heart arteries and veins, 5th ed. McGraw-Hill, New York, pp 1299-1362

Hastreiter AR (1968) Endocardial fibroelastosis. In: Moss AJ, Adams FH (eds) Heart disease in infants, children and adolescents, 1st ed. Williams \& Wilkins Co, Baltimore, pp 760-797

Höck A, Freundlieb C, Vyska K, Lösse B, Erbel R, Feinendegen LE (1983) Myocardial imaging and metabolic studies with $\left[17-{ }^{123} \mathrm{I}\right]$ iodoheptadecanoic acid in patients with idiopathic congestive cardiomyopathy. J Nucl Med 24:22-28

Kearns TP, Sayre GP, Minn R (1958) Retinitis pigmentosa, external ophthalmoplegia and complete heart block. Arch Ophthalmol 60:280-289

Klein MS, Goldstein RO, Welch MJ, Sobel BE (1979) External assessment of myocardial metabolism with $\left[{ }^{11} \mathrm{C}\right]$ palmitate in rabbit hearts. Am J Physiol 237:H51-H58

Lanzkowsky P, Erlandson ME, Bezan AI (1969) Isolated defect of folic acid absorption associated with mental retardation and cerebral calcification. Blood 34:452-465

Lerch RA, Ambos HD, Bergmann SR, Welch MJ, Ter-Pogossian MM, Sobel BE (1981) Localization of viable, schemic myocardium by positron-emission tomography with ${ }^{11} \mathrm{C}$-palmitate. Circulation 64:689-699

Lerch RA, Bergmann SR, Ambos HD, Welch MJ, Ter-Pogossian MM, Sobel BE (1982) Effect of flow independent reduction of metabolism on regional myocardial clearance of ${ }^{11} \mathrm{C}$-palmitate. Circulation 65:731-738

Machulla H-J, Stocklin G, Kupfernagel CH, Freundlieb C, Höck A, Vyska K, Feinendegen LA (1978) Comparative evaluation of fatty acids labeled with C-11, C1-34m, Br-77, and I-123 for metabolic studies of the myocardium: Concise communication. J Nucl Med 19:298-302

Mastaglia FL, Thompson PL, Papadimitriu JM (1980) Mitochondrial myopathy with cardiomyopathy, lactic acidosis and response to prednisone and thiamine. Aust NZ J Med 10:660664

McGarry JD, Foster DW (1976) An improved and simplified radioisotopic assay for the determination of free and esterified carnitine. J Lipid Res 17:277-281

Melvin KR, Mason JW (1982) Endomyocardial biopsy: its history, techniques and current indications. Can Med Assoc J 126:1381-1386

Okada RD, Elmaleh D, Werre IS, Strauss HW (1983) Myocardial kinetics of ${ }^{123}$ I-labeled-16-hexadecanoic acid. Eur J Nucl Med $8: 211-217$

Otto CA, Brown LE, Wieland DM, Beierwaltes WH (1981) Radioiodinated fatty acids for myocardial imaging: effects of chain length. J Nucl Med 22:613-618

Perloff JK, Henze E, Schelbert HR (1984) Alterations in regional myocardial metabolism, perfusion and wall motion in Duchenne muscular dystrophy studies by radionuclide imaging. Circulation 69:33-42

Peters TJ, Wells J, Oakley CM (1977) Enzymatic analysis of endomyocardial biopsy specimens from patients with cardiomyopathies. Br Heart J 39:1333-1339

Rothenberg SP, da Costa M, Rosenberg Z (1972) A radio assay 
for serum folate: Use of a two phase sequential-incubation, ligand-binding system. N Engl J Med 286:1335-1339

Schelbert HR, Henze E, Schön HR, Keen R, Hansen H, Selin C, Huang S-C, Barrio JR, Phelps ME (1983) C-11 palmitate for the noninvasive evaluation of regional myocardial fatty acid metabolism with positron computed tomography. III. In vivo demonstration of the effects of substrate availability on myocardial metabolism. Am Heart J 105:492-504

Schön HR, Schelbert HR, Robinson G, Najafi A, Huang S-C, Hansen H, Barno J, Kuhl DC, Phelps ME (1982) C-11 labeled palmitic acid for the noninvasive evaluation of regional myocardial fatty acid metabolism with positron-computed tomography. 1. Kinetics of C-11 palmitic acid in normal myocardium. Am Heart J 103:532-547

Taylor WJ (1982) Genetics and the cardiovascular system. In: Hurst JW (ed) The heart arteries and veins, 5th ed. McGrawHill, New York, pp 630-642

Tripp ME, Katcher ML, Peters HA, Gilbert EF, Arya S, Hodach RJ, Shug AL (1981) Systemic carnitine deficiency presenting as familial endocardial fibroelastosis. $N$ Engl J Med $305: 385-390$ van der Wall EE, den Hollander W, Heidendal GAK, Westera G, Majid PA, Roos JP (1981) Dynamic myocardial scintigraphy with ${ }^{123} \mathrm{I}$ labeled free fatty acids in patients with myocardial infarction. Eur J Nucl Med 6:383-389

van der Wall EE, Heidendal GAK, den Hollander W, Roos JP (In press) Myocardial scintigraphy with ${ }^{123} \mathrm{I}$-labeled heptadecanoic acid in patients with unstable angina pectoris. Amsterdam, Academisch Proefschrift

van der Wall EE, Heidendal GAK, den Hollander W, Westera G, Roos JP (1981) Metabolic myocardial imaging with ${ }^{123}$ Ilabeled heptadecanoic acid in patients with angina pectoris. Eur J Nucl Med 6:391-396

Watson DD, Campbell NP, Read EK, Gibson RS, Teates CD, Beller GA (1981) Spatial and temporal quantitation of plane thallium myocardial images. J Nucl Med 23:577-584

Westwood M, Harris R, Burn JL, Barson AJ (1975) Heredity in primary endocardial fibroelastosis. Br Heart J 37:1077-1084

Received February 18, 1984 / July 20, 1984 